\title{
A Clinicopathological Evaluation of Male Patients with Breast Cancer
}

\author{
Enver Ilhan ${ }^{a}$ Bakir Bati $^{\mathrm{b}} \quad$ Ali Alemdar $^{\mathrm{b}} \quad$ Ali Coskun $^{\mathrm{a}} \quad$ Arsenal Sezgin $^{\mathrm{c}} \quad$ Mehmet Yildirim $^{\mathrm{a}}$ \\ Omer Engin ${ }^{\text {a }}$ Mete Purten ${ }^{\mathrm{a}}$
}

a Department of General Surgery, Izmir Bozyaka Education and Research Hospital,

${ }^{b}$ Department of General Surgery, Istanbul Okmeydani Education and Research Hospital,

${ }^{c}$ Department of Pathology, Izmir Bozyaka Education and Research Hospital, Turkey

\section{Key Words}

Breast cancer - Male breast cancer · Neoplasm

\section{Summary}

Background: Although male breast cancer constitutes only $1 \%$ of all breast cancers, its incidence is increasing and it is becoming an important public health issue. The present study aims to present the clinicopathological characteristics of surgically treated male breast cancer patients from multiple centers. Patients and Methods: Twenty-one male patients operated on for breast cancer were retrospectively examined in terms of clinical presentation, pathological characteristics, TNM staging status, and type of surgical treatment. Results: The mean age of the 21 patients was 62.3 years (range 38-94), with the majority being in the range of $50-69$ years $(61.9 \%)$. The most frequent finding was breast mass (85.7\%). Most patients underwent modified radical mastectomy $(76.1 \%)$, and the most prevalent histological type was invasive ductal carcinoma (85.7\%). The majority of patients had stage II or III disease, and estrogen receptors were positive in 18 (85.7\%) of the patients. Conclusion: Since male breast cancer is a rare condition, it is challenging to conduct prospective randomized trials. Currently, there is a lack of comprehensive data on the diagnosis and management of this condition. Thus, further studies and the implementation of specific guidelines or protocols for this subgroup of patients will aid better management.

\author{
Schlüsselwörter \\ Mammakarzinom - Brustkrebs des Mannes · Neoplasie
}

\section{Zusammenfassung}

Hintergrund: Obwohl der Brustkrebs des Mannes nur 1\% aller Mammakarzinome ausmacht, ist die Inzidenz doch steigend, und die Erkrankung entwickelt sich zu einem für das Gesundheitswesen bedeutenden Problem. Ziel der vorliegenden Studie ist es, die klinisch-pathologischen Charakteristika chirurgisch behandelter männlicher Brustkrebspatienten verschiedener Zentren darzustellen. Patienten und Methoden: Insgesamt wurden 21 chirurgisch behandelte Brustkrebspatienten retrospektiv bezüglich ihrer klinischen Präsentation, pathologischen Charakteristika, TNM-Status und Art der chirurgischen Behandlung ausgewertet. Ergebnisse: Das mittlere Alter der 21 Patienten war 62,3 Jahre (Spanne 38-94); die Mehrzahl der Patienten war 50-69 Jahre alt (61,9\%). Der häufigste Befund war Brusttumor (85,7\%). Bei den meisten Patienten wurde eine modifizierte, radikale Mastektomie durchgeführt $(76,1 \%)$, und der häufigste histologische Befund war invasives duktales Karzinom (85,7\%). Die Mehrzahl der Patienten war im Stadium II oder III. 18 (85,7\%) Patienten waren östrogenrezeptorpositiv. Schlussfolgerung: Da der Brustkrebs des Mannes eine seltene Erkrankung ist, ist es schwierig, prospektive randomisierte Studien durchzuführen, und im Moment mangelt es an umfassenden Daten zu Diagnose und Management. Weitere Studien sowie die Implementierung spezifischer Richtlinien oder Protokolle für diese Patientenuntergruppe würden deshalb das Management dieser Erkrankung erleichtern.

\begin{tabular}{ll}
\hline KARGER & ( 2009 S. Karger GmbH, Freiburg \\
$\begin{array}{l}\text { Fax +497614520714 } \\
\text { Information@Karger.de } \\
\text { www.karger.com }\end{array}$ & $\begin{array}{l}\text { Accessible online at: } \\
\text { www.karger.com/brc }\end{array}$
\end{tabular}

\section{KARGER}

www.karger.com/brc 


\section{Introduction}

Male breast cancer is a rare condition with an increasing incidence, and several factors might play a role in its development. Although the exact cause is not clearly known, increased male life expectancy and awareness about male breast cancer may be responsible for the increasing incidence of the disease [1]. Male patients present at more advanced stages when compared to women, and surgery is the preferred treatment modality. Hormone receptors are positive in most patients. As it is a rare condition, it is almost impossible to conduct randomized controlled trials. The number of cases is also too limited to allow retrospective studies. It is presumed that male breast cancer displays behaviors similar to those in postmenopausal women with breast cancer, and the protocols for female breast cancer are used in the followup [2]. The present study aims to carry out a retrospective examination of male breast cancer patients and underline the importance of the issue in the context of its increasing incidence.

\section{Materials and Methods}

\section{Patients}

A total of 21 male breast cancer patients from multiple institutions operated on between the years 1998 and 2008 were included in this retrospective multicenter study. Patient records were examined for age, clinical findings, laterality, imaging methods, methods for tissue diagnosis, tumor diameter, type of operation, early postoperative complications, lymph node involvement, histological tumor type, histological grade, classification, grading, and positivity of hormone receptors. Nineteen patients did not have distant metastasis, and 2 had bone metastasis. These patients were operated on in order to prevent local complications, such as abscess formation, fistulization, or ulceration. Cases with recurrent breast cancer were not included.

\section{Diagnostic Methods}

Patients were first evaluated by history and physical examination, and then a radiological examination was carried out with ultrasonography and/or mammography. For the histological diagnosis, fine needle aspiration biopsy (FNAB), core biopsy, excisional biopsy, or frozen section were performed based on the individual characteristics of each case and the discretion of the attending surgeon. FNAB specimens were examined after hematoxylin and eosin and PAP staining. Core biopsy specimens were examined as a whole, but excisional biopsy specimens were sampled based on the macroscopic size of the tumor (a tissue sample for each 1 $\mathrm{cm}$ of diameter). For mastectomy materials, 2-6 samples were obtained from the tumor, and at least 1 sample was taken from each quadrant and from the nipple. Following standard preparation procedures, tissues were embedded in paraffin blocks. Then, 4-5 $\mu \mathrm{m}$ thick sections were made and stained with hematoxylin and eosin to be examined under a light microscope. Histological grading of the tumor was done using a modified Bloom-Richardson grading system. Estrogen and progesterone receptors were assessed immunohistochemically. C-erbB-2 (HER-2/neu) status was assessed as follows: no or less than $10 \%$ staining in tumor cell membranes (score 0, HER-2/neu-); greater than $10 \%$ but partial staining (score $1+$, HER-2/neu-); weak-moderate complete staining greater than $10 \%$ (score $2+$, HER-2/neu weak + ), strong-positive staining greater than $10 \%$ (score $3+$, HER-2/neu strong + ).

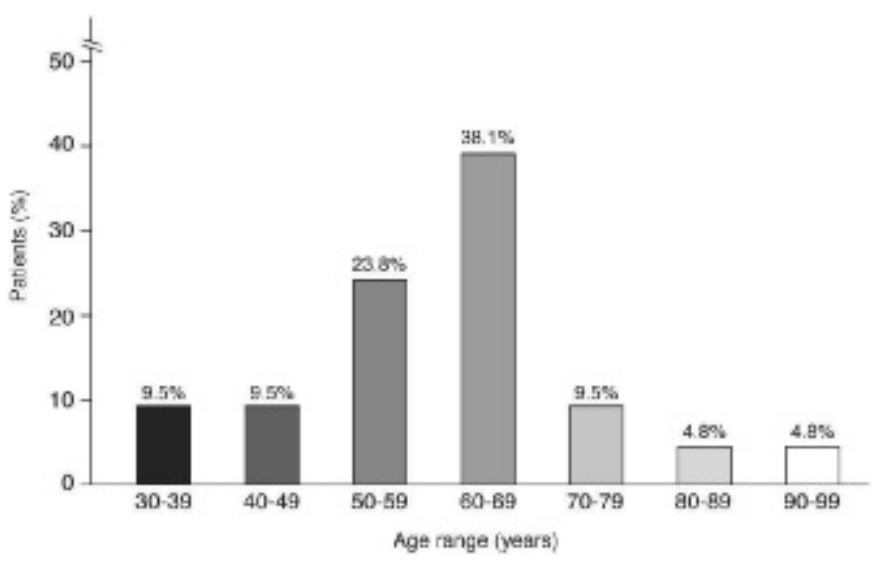

Fig. 1. Distribution of male breast cancer patients by age groups.

\section{Surgical Treatment}

After histological confirmation of malignant disease, modified radical mastectomy, radical mastectomy, or salvage mastectomy was carried out at the discretion of the surgeon based on individual disease characteristic of each patient. In modified radical mastectomy, mammary tissue and pectoralis fascia were removed together with level 1 and level 2 lymph nodes, leaving pectoralis major and pectoralis minor muscles. Radical mastectomy included also the removal of these 2 muscles. In some patients, salvage mastectomy including the sole resection of mammary tissue was done. As the patients were male with low breast volumes and due to the frequent subareolar location of the tumors, breast conserving surgery was not performed in any of the patients.

\section{Staging}

Clinical staging of the patients based on the TNM (tumor, node, and metastasis) classification of the American Joint Committee on Cancer (AJCC) was done using patient information on tumor size, axillary lymph node involvement, and distant metastasis. All data are presented as numbers (n) and percentages (\%).

\section{Results}

\section{Patients}

The mean age of the 21 male breast cancer patients was 62.3 years (range 38-94), with the majority being in the age groups of 50-59 (23.8\%) and 60-69 years (38.1\%) (fig. 1). The most frequent clinical finding was breast mass $(85.7 \%)$; the frequencies of other signs and symptoms are shown in table 1 . Tumor location was subareolar in $19(90.4 \%)$ of the cases. Breast cancer was located on the right side in $11(52.3 \%)$ cases and on the left side in $10(47.7 \%)$ cases.

\section{Diagnostic Methods}

For radiological imaging of the tumors, 9 (42.8\%) cases underwent both mammography and ultrasonography, and 12 $(57.2 \%)$ cases had only ultrasonography. Findings in favor of malignant disease were obtained in $90.4 \%$ of mammographies and in $75 \%$ of ultrasonography examinations. For tissue diagnosis, FNAB, core biopsy, excisional biopsy, and frozen section were performed in 4 (19\%), 6 (28.5\%), 9 (42.9\%), and 2 $(9.6 \%)$ cases, respectively. 
Table 1. Clinical characteristics and histological type of male breast cancer patients

\begin{tabular}{lc}
\hline Characteristic & Patients, $\mathrm{n}(\%)$ \\
\hline Presentation & $18(85.7)$ \\
Breast mass & $4(19.0)$ \\
Hemorrhagic nipple discharge & $4(19.0)$ \\
Mastalgia & $4(19.0)$ \\
Retraction of the nipple & $2(9.5)$ \\
Axillary lymphadenopathy & $2(9.5)$ \\
Skin ulcer & \\
Histological type & $1(4.8)$ \\
Minimal invasive carcinoma & $1(4.8)$ \\
Invasive ductal carcinoma + invasive papillary carcinoma & $1(4.8)$ \\
Invasive ductal carcinoma + in situ ductal carcinoma & \\
$\quad+$ intraductal papillary carcinoma & $1(4.8)$ \\
Invasive ductal carcinoma + florid gynecomastia & $1(4.8)$ \\
Intracystic papillary carcinoma & $1(4.8)$ \\
Invasive ductal carcinoma + Paget's disease of the nipple & $1(4.8)$ \\
Mucinous carcinoma & $14(66.7)$ \\
Invasive ductal carcinoma &
\end{tabular}

Table 2. Staging of the male breast cancer patients according to the TNM classification of American Joint Committee on Cancer (AJCC)

\begin{tabular}{ll}
\hline AJCC Stages & Patients, $\mathrm{n}(\%)$ \\
\hline Stage I & \\
Total & $4(19.0)$ \\
T1N0M0 & $4(19.0)$ \\
Stage II & \\
Total & $7(33.3)$ \\
T2N0M0 & $3(14.3)$ \\
T2N1Mo & $4(19.0)$ \\
Stage III & \\
Total & $8(38.1)$ \\
T2N2M0 & $2(9.5)$ \\
T3N0M0 & $2(9.5)$ \\
T3N1M0 & $1(4.8)$ \\
T3N2M0 & $1(4.8)$ \\
T4N2M0 & $2(9.5)$ \\
Stage IV & \\
Total & $2(9.5)$ \\
T2N2M1 & $1(4.8)$ \\
T3N2M1 & $1(4.8)$ \\
\hline
\end{tabular}

\section{Surgical Treatment}

Modified radical mastectomy was performed in $16(76.2 \%)$ cases, and radical mastectomy was done in $3(14.3 \%)$ patients. In $2(9.5 \%)$ patients with distant metastasis demonstrated by whole-body bone scintigraphy, salvage mastectomy was performed. During the early postoperative period, 1 (4.8\%) case developed hematoma, and 2 (9.5\%) cases developed ischemia at the site of incision; all were treated with conservative methods.

\section{Histological Evaluation and TNM Staging}

Mean tumor diameter was $3.1 \mathrm{~cm}$ (range 0.1-6). Invasive ductal carcinoma was the most common histological diagnosis
Table 3. Treatments of the patients

\begin{tabular}{ll}
\hline Treatment modality & Patients, $\mathrm{n}$ \\
\hline HT alone & 5 \\
HT plus CT plus RT & 9 \\
CT plus HT & 5 \\
CT plus RT & 2 \\
\hline
\end{tabular}

$\mathrm{HT}=$ Hormone therapy; $\mathrm{CT}=$ chemotherapy; $\mathrm{RT}=$ radiotherapy .

present in $18(85.7 \%)$ of the cases. Other histological types are depicted in table 1. Distribution of patients by histological grade was as follows: histological grade I in 4 (19\%) patients, histological grade II in $12(57.2 \%)$ patients, and histological grade III in $5(23.8 \%)$ patients. The number of lymph nodes found in the cases ranged between 3 and 28 , and lymph node involvement was present in $11(52.3 \%)$ cases. The mean number of metastatic lymph nodes was 3.6 (range 1-11). Distribution of patients by AJCC TNM staging is shown in table 2, with the majority of the patients at stage II or III. Estrogen and progesterone receptors were positive in 18 (85.7\%) and 17 $(80.9 \%)$ cases, respectively. 2 (9.6\%) cases were hormone receptor-negative. Immunohistochemical evaluation was available in 8 patients, and 4 of them were positive for C-erbB-2.

\section{Treatment, Prognosis, and Survival}

Hormone therapy was given to all patients with positive hormone receptor status. Chemotherapy and radiotherapy were administered in accordance with breast cancer treatment protocols for women (table 3). The average duration of follow-up was 66 months. 4 patients died due to disease activity, and 1 due to concurrent conditions. 4 patients are alive with systemic metastases. The most frequent site of metastasis was bone, followed by the lungs. No locoregional recurrence was 
Table 4. 5-year overall survival rates by patient characteristics

observed. 5-year overall survival was $76.2 \%$, and 5-year disease-specific survival was $80.9 \%$. The average diameter of the tumor in patients who died or are living with metastases was $3.9 \mathrm{~cm}$, with age, lymph node involvement, and stage being the major determinants of 5-year overall survival (table 4).

\section{Discussion}

Breast cancer rarely occurs in males, and a total of 21 patients from multiple centers could be recruited for the present study. When compared to previous data for female breast cancer patients, our patients were at a higher stage at the time of admission, and they had higher rates of axillary lymph node metastasis and estrogen/progesterone receptor positivity. Clearly, multicenter prospective studies using common protocols and focusing on early diagnosis and treatment are required.

Male breast cancer constitutes $1 \%$ of all breast cancers, and its prevalence has been on a continuous rise for the last 25 years. Making a peak approximately between the ages of 60 and 65 , it occurs 10 years later than female breast cancer [1, 3-6]. In the study by Giordano et al. [6], the mean age of male breast cancer patients was 67 years (range 10-103), and the corresponding figure for female patients was 62 years (range 11-108). In the large female breast cancer series by Nahleh et al. [7], the mean age at the time of diagnosis was 57 years. In the present study, the mean age of male breast cancer patients was 62.3 years (range 38-94), with a peak prevalence between the ages of 60-69. Breast cancer may be seen in either the right or left breast; however, the disease has a slight tendency to occur on the left side. In the present study, rates for right-sided and left-sided tumors were 52.3 and $47.7 \%$, respectively, with a slight tendency towards the right side. Nevertheless, we found an almost equal preponderance of the two sides (left-to-right ratio 1:1.09), in line with previous reports (1.07:1) [1-5, 8].

Risk factors for male breast cancer include the following: susceptibility to BRCA2 genetic mutation, benign breast dis- eases, advanced age, Jewish origin, black race, positive family history, higher socioeconomic and educational status, lack of children, unmarried status, testicular function defects due to chromosomal anomalies such as Klinefelter's syndrome resulting in increased estrogen levels, obesity, excessive alcohol consumption, liver cirrhosis, exposure to chronic heat, radiation and polluting gases, and other occupational and environmental factors. Male breast cancer may be associated with undescended testicles or congenital hernia $[1,3,5,9]$, as was the case with one of our patients. Detailed history and physical examination of that patient, who was histologically diagnosed with minimally invasive carcinoma based on excisional biopsy, disclosed a previous operation for congenital inguinal hernia. A positive family history has been reported to increase the risk of male breast cancer by factor 2-3 [10]. However, in the present study, no history of breast or ovarian cancer was detected among the female members of the families. There is a linkage between the BRCA2 gene and breast cancer-prone families in whom male breast cancer cases have occurred, and BRCA2 may be a useful marker for identifying males who are at increased risk. For men, the frequency of BRCA2 mutations is estimated to be between 4 and $40 \%$. In patients with BRCA2 mutations, male breast cancer tends to present at a younger age and may be associated with poorer survival [11]. However, BRCA2 has not been examined in the present study. Gynecomastia is a common condition being present in $30-50 \%$ of healthy men $[12,13]$. Although gynecomastia is not considered a risk factor, the issue is still controversial [1,9]. One of our cases with invasive ductal carcinoma had gynecomastia (4.8\%). Gynecomastia rates of 6-30\% have been reported for male breast cancer patients [14]. In the study by Brinton et al. [15] recruiting a total of 642 males with breast cancer, the relative risk and confidence interval for gynecomastia were 5.86 and 3.74-9.17, respectively. These authors used additional multivariate models $(5.08,3.21-8.03)$ to conclude that gynecomastia was a significant risk factor for male breast cancer. Factors underlying the development of male breast cancer are particularly hormonal and environmental changes, and abnormal endocrine function also plays a role. Retrospective studies indicate that increased estrogen and decreased androgen levels may be concurrently seen in male breast cancer [16].

Most breast cancer patients present with a hard and painless subareolar mass larger than $2 \mathrm{~cm}$ which may be fixed to skin [4]. In our series, similarly to previous studies, the mean tumor diameter at the time of admission was $3.1 \mathrm{~cm}$. Interestingly, in one of our patients presenting with hemorrhagic nipple discharge, the tumor diameter was $0.3 \mathrm{~cm}$. In most of our cases, tumor location was subareolar $(90.4 \%)$, similar to the previously reported rates of 70-90\%. Distant metastasis was found in $2(9.5 \%)$ of our patients at the time of diagnosis, which is relatively close to previously reported rates for males $(6.9 \%)$ but higher than what was reported for females (5.6\%) [6].

When compared to female patients with breast cancer, male patients present at an advanced stage and usually have 
higher mortality rates. Advanced disease is characterized by pain, skin ulceration, and bloody nipple discharge $[8,17,18]$. Staging of our patients was as follows: stage $0,0 \%$; stage I, $19 \%$; stage II, $33.3 \%$; stage III, $38.1 \%$; stage IV, $9.5 \%$; unknown stage, $0 \%$. In the study by Giordano et al. [6], the corresponding figures were $10.5,29.4,38.5,7.5,5.7$, and $8.5 \%$ for male patients, and 14.4, 38.4, 27.7, 5.3, 3.9, and 7.4\% for female patients. Nahleh et al. [7] also found a similar distribution pattern: for males $6.2,22.7,39.6,12.8,8.9$, and $10 \%$, and for females $15.8,30.9,29.2,8.2,6.1$, and $10 \%$. The increased number of stage III tumors among our patients may be a reflection of the absence of any stage 0 tumor or any case with an unknown stage. As breast cancer is commonly regarded as a disease of women, the possibility of breast cancer may have been overlooked by our patients when a breast mass was recognized, thus resulting in a delayed diagnosis, which may also partly explain our slightly different stage distribution.

In the evaluation of breast cancer, ultrasonography typically shows microlobulated irregular masses and plays an important role in grading lymph nodes. Mammography shows spiculated irregular masses or masses with unclear borders; and gynecomastia or calcifications may also be evident. Calcifications are typically pleomorphic and segmental [19]. In contrast to women, all calcifications in male mammographies should be considered as malignant [20]. Magnetic resonance imaging findings in male breast cancer are similar to those in female breast cancer [21]. Of our cases, 9 (42.8\%) had both mammography and ultrasonography, and 12 (57.2\%) had only ultrasonography. Findings in favor of a malignant disease were obtained in $90.4 \%$ of mammographies and in $75 \%$ of ultrasonography examinations.

In most male patients presenting with a breast mass, evaluation should certainly involve tissue diagnosis [22]. Clinical evaluation through biopsy is fundamental in the diagnosis, and FNAB is the primary method [16]. In our cases, FNAB was done in $4(19 \%)$ cases, which may be considered an insufficient use of this method. Modified radical mastectomy is the basic and standard surgical approach $[4,17]$. Lymph node dissection should be done as conventional axillary lymph node dissection (ALND) or sentinel lymph node dissection (SLND), similar to female breast cancer cases [23, 24]. We performed modified radical mastectomy $(76.1 \%, \mathrm{n}=16)$, radical mastectomy $(14.2 \%, \mathrm{n}=3)$, and salvage mastectomy $(9.5 \%, n=2)$. As similar local recurrence rates have been obtained with radical or modified radical mastectomy in previous studies [25], we mostly preferred the latter. SLND was not performed in any of our patients. Since available data on this issue are limited, a randomized trial seems to be needed in this specific setting. Gentilini et al. [26] retrospectively evaluated 32 clinically axillary node-negative patients undergoing sentinel node biopsy (SNB) among a total of 75 participants surgically treated for breast cancer and found negative axillary involvement in 26. These authors suggested that SLNB is a safe treatment option and should be considered as first-line treatment to avoid unnecessary ALND and complications in subjects with clinically negative axillary involvement. According to a panel of the American Society of Clinical Oncology, it is unlikely that SNB will be any less accurate in men than it is in women. However, the panel concludes that there are limited data to make categorical recommendations about the use of SNB for men with breast cancer [27]. In our study, SLND was not performed based on the preference of the surgeon and due to technical limitations.

As the remaining breast volume is usually sufficient for male patients, breast conserving surgery is not recommended; however, studies on reconstruction have recently been reported $[1,3]$. In the early postoperative period, 1 (4.8\%) of our cases developed hematoma, and $2(9.5 \%)$ cases developed ischemia at the site of the incision line; both were treated with conservative methods.

Most of the cases had invasive ductal carcinoma and about $10 \%$ had ductal carcinoma in situ. In the order of frequency, invasive ductal carcinoma is followed by papillary carcinoma $[2,4,9,16]$. Similar to previously reported rates, $18(85.7 \%)$ of our patients had invasive ductal carcinoma. On the other hand, $3(14.2 \%)$ patients had papillary formation, which was substantially more than what was reported in previous studies: 2.6 and $0.6 \%$ for male and female breast cancer patients, respectively [6]. In line with previous reports (5\%) [28], Paget's disease was present in $4.8 \%$ of our patients.

Histological grading of our cases was as follows: HG I, 19\%; HG II, 57.2\%; and HG III, 23.8\%. In a large series, rates of HG I, HG II, HG III, and unknown HG were 11.1, 35.6, 21.9, and $31.3 \%$ for male breast cancer cases. For females, the corresponding figures were $12.3,26.4,22.9$, and $38.5 \%$ [7]. The relatively high rate of patients with unknown histological grade in that study may explain the dissimilarity with our figures.

Owing to the lack of comprehensive randomized studies, optimal management in male breast cancer is not yet established. Breast cancer is similar in men and women; however, male breast cancer is frequently accompanied by hormone receptor positivity and may be more responsive to hormonal treatment [5]. In the present study, $85.7 \%$ of male breast cancer patients were positive for estrogen receptors. In a large series of patients, estrogen receptor was positive in 90.6 and $76.0 \%$ of male and female breast cancer cases, respectively [6]. In that study, $81.2 \%$ of male patients and $66.7 \%$ of female patients were positive for progesterone receptor. Our positive estrogen receptor rate was similar to that obtained in previous studies for male breast cancer patients, but higher than the reported rates for female patients. A limited number of studies have examined the role of HER-2/neu in male breast cancer. In our study, C-erbB-2 positivity was investigated in 8 patients, with $2+, 3+$, and $1+$ scores in 1,1 , and 2 patients, respectively; and HER-2/neu overexpression was found in $25 \%$ (2/8). In a recent study by Rudlowski et al. [29] this figure was reported to be $15.1 \%(15 / 99)$. The higher percentage of patients with HER-2 overexpression in our study might be explained on the 
basis of the small sample size. The C-erbB-2 positivity reported by Giordano et al. [5] was 37.2\% (190/511).

Systemic chemotherapy is used both in hormone-negative patients and in those who resist endocrine treatment [18]. Hormonal treatment is the primary treatment method for patients with metastasis. The role of radiotherapy after mastectomy in men has not been well-defined; however, it should be used in patients with a high risk of local recurrence [22]. In our study, all hormone receptor-positive patients received hormone therapy, and appropriately selected subjects received chemotherapy and radiotherapy similar to treatment protocols used for female breast cancer patients.

The prognostic factors in male breast cancer include tumor diameter, type of the surgical treatment, histological grade, and lymph node involvement [5, 14]. Lymph node involvement is an important feature and was present in $57.1 \%$ of our cases, compared to previously reported rates of $37.3-56.0 \%$ and $28.2-29.2 \%$ for male and female breast cancer cases, respectively $[6,7,30]$. The high lymph node involvement rate observed in the present study may be attributed to the delayed admission to hospital resulting in the diagnosis of the patients at a more advanced age. Our overall 5-year survival data and their relation to clinicopathological parameters are consistent with previously reported data $[6,11,31]$. On the other hand, the slightly higher percentage of patients remaining alive in each stage might be related to small sample size, while the shorter survival in estrogen receptor-positive patients was probably associated with the higher proportion of subjects with estrogen receptor positivity. Advanced age, greater tumor diameter, lymph node involvement, and advanced stage of the disease are associated with poorer survival.

The relatively small number of patients in the present study represents a limitation. However, male breast cancer is a rare condition, and individual cases are mostly managed according to the protocols for female breast cancer at different healthcare institutions. Thus, currently, there is a lack of comprehensive data on the diagnosis and management of this condition. Most of the male breast cancer cases are considered sporadic, and in the usual practice setting, a general surgeon encounters only a few male breast cancer cases in his/her lifetime, if any at all. This is associated with the paucity of data on this condition reflected by this series with a low number of patients. Thus, we wish to present our data on male breast cancer patients to the medical community to make a contribution to further studies. We therefore aimed to pool and present the data from multiple institutions and discuss them in the context of previous findings of male and/or female breast cancer studies.

\section{Conclusion}

The clinicopathological examination of our male breast cancer patients revealed that the disease was presented at an advanced stage, making management rather challenging. These patients also had a high rate of hormone receptor positivity. Increased awareness and early management of male breast cancer would be expected to result in better outcomes. The dissimilarities between male and female breast cancers should be revealed. Thus, conducting multicenter clinical studies and implementing specific guidelines or protocols for this subgroup of patients will facilitate early diagnosis and more effective treatment.

\section{Conflict of Interest}

The authors indicate that they have no interest which may be perceived as posing a conflict or bias.

\section{References}

1 Fentiman IS, Fourquet A, Hortobagyi GN: Male breast cancer. Lancet 2006;18:367:595-604.

2 Wernberg JA, Yap J, Murekeyisoni C, Mashtare T, Wilding GE, Kulkarni SA: Multiple primary tumors in men with breast cancer diagnoses: a SEER database review. J Surg Oncol 2009;99:16-19.

$\checkmark 3$ Agrawal A, Ayantunde AA, Rampaul R, Robertson JF: Male breast cancer: a review of clinical management. Breast Cancer Res Treat 2007;103:11-21.

4 Kuroi K, Toi M: Male breast cancer. Gan To Kagaku Ryoho 2003;30:599-605.

5 Giordano SH, Buzdar AU, Hortobagyi GN: Breast cancer in men. Ann Intern Med 2002;15:137:678 687.

6 Giordano SH, Cohen DS, Buzdar AU, Perkins G, Hortobagyi GN: Breast carcinoma in men: a population-based study. Cancer 2004;101:51-57.

7 Nahleh ZA, Srikantiah R, Safa M, Jazieh AR, Muhleman A, Komrokji R: Male breast cancer in the veterans affairs population: a comparative analysis. Cancer 2007;109:1471-1477.
8 Ewertz M, Holmberg L, Karjalainen S, Tretli S, Adami HO: Incidence of male breast cancer in Scandinavia, 1943-1982. Int J Cancer 1989;43: 27-31.

9 Meguerditchian AN, Falardeau M, Martin G: Male breast carcinoma. Can J Surg 2002;45:296-302.

10 Ewertz M, Holmberg L, Tretli S, Pedersen BV, Kristensen A: Risk factors for male breast cancer-a casecontrol study from Scandinavia. Acta Oncol 2001;40: 467-471.

11 Rudlowski C: Male breast cancer. Breast Care 2008;3:183-189.

12 Bembo SA, Carlson HE: Gynecomastia: its features, and when and how to treat it. Cleve Clin J Med 2004;71:511-517.

13 Gikas P, Mokbel K: Management of gynaecomastia: an update. Int J Clin Pract 2007;61:1209-1215.

14 Yildirim E, Berberoglu U: Male breast cancer: a 22-year experience. Eur J Surg Oncol 1998;24:548552.
15 Brinton LA, Carreon JD, Gierach GL, McGlynn KA, Gridley G: Etiologic factors for male breast cancer in the U.S. Veterans Affairs medical care system database. Breast Cancer Res Treat 2009, Epub ahead of print.

16 Wagner JL, Thomas CR Jr, Koh WJ, Rudolph RH: Carcinoma of the male breast: update 1994. Med Pediatr Oncol 1995;24:123-132.

17 Bergs EA, Tanis PJ, Steller EP: Three men with breast cancer. Ned Tijdschr Geneeskd 2005;149: 534-537.

18 Xue Y, Guo XT, Liu WC: Clinical research advancement on male breast cancer. Ai Zheng 2007;26: 1148-1152.

19 Mathew J, Perkins GH, Stephens T, Middleton LP, Yang WT: Primary breast cancer in men: clinical, imaging, and pathologic findings in 57 patients. AJR Am J Roentgenol 2008;191:1631-1639.

20 Dershaw DD, Borgen PI, Dutch BM, Liberman I: Mammographic findings in men with breast cancer. AJR 1993;160:267-270. 
21 Morakkabati-Spitz N, Schild HH, Leutner CC, von Falkenhausen M, Lutterbey G, Kuhl CK: Dynamic contrast-enhanced breast MR imaging in men: preliminary results. Radiology 2006;238:438-445.

22 Buzdar AU: Breast cancer in men. Oncology (Williston Park) 2003;17:1361-1364.

23 Boughey JC, Bedrosian I, Meric-Bernstam F, Ross MI, Kuerer HM, Akins JS, Giordano SH, Babiera GV, Ames FC, Hunt KK: Comparative analysis of sentinel lymph node operation in male and female breast cancer patients. J Am Coll Surg 2006;203: 475-480.

24 Volm MD: Male breast cancer. Curr Treat Options Oncol 2003;4:159-164.

25 Ouriel K, Le MT, Hinshaw JR: Prognostic factors of carcinoma of the male breast. Sur Gynecol Obstet 1984;159:373-376.

26 Gentilini O, Chagas E, Zurrida S, Intra M, De Cicco C, Gatti G, Silva L, Renne G, Cassano E, Veronesi U: Sentinel lymph node biopsy in male patients with early breast cancer. Oncologist 2007;12: 512-515.

27 Lyman GH, Giuliano AE, Somerfield MR, Benson AB 3rd, Bodurka DC, Burstein HJ, Cochran AJ, Cody HS 3rd, Edge SB, Galper S, Hayman JA, Kim TY, Perkins CL, Podoloff DA, Sivasubramaniam VH, Turner RR, Wahl R, Weaver DL, Wolff AC, Winer EP; American Society of Clinical Oncology: American Society of Clinical Oncology guideline recommendations for sentinel lymph node biopsy in early-stage breast cancer. J Clin Oncol 2005;23:7703-7720.

28 Lanitis S, Rice AJ, Vaughan A, Cathcart P, Filippakis G, Al Mufti R, Hadjiminas DJ: Diagnosis and management of male breast cancer. World J Surg 2008;32:2471-2476.

29 Rudlowski C, Friedrichs N, Faridi A, Füzesi L, Moll R, Bastert G, Rath W, Büttner R: Her-2/neu gene amplification and protein expression in primary male breast cancer. Breast Cancer Res Treat 2004;84:215-223.

-30 Cutuli B, Lacroze M, Dilhuydy JM, Velten M, De Lafontan B, Marchal C, Resbeut M, Graic Y, Campana F, Moncho-Bernier V et al.: Male breast cancer: results of the treatments and prognostic factors in 397 cases. Eur J Cancer 1995;31A:1960.

31 Cutuli B, Le-Nir CC, Serin D, Kirova Y, Gaci Z, Lemanski C, De Lafontan B, Zoubir M, Maingon P, Mignotte H, Lara CT, Edeline J, Penault-Llorca F, Romestaing P, Delva C, Comet B, Belkacemi Y: Male breast cancer. Evolution of treatment and prognostic factors. Analysis of 489 cases. Crit Rev Oncol Hematol 2009, Epub ahead of print. 